\title{
A ESCRITA DE VERBETES PARA A ENDICI: PRIVADO E PRIVACIDADE
}

\section{MARCOS AURÉLIO BARBAI ${ }^{1}$; MARIA FERNANDA MOREIRA ${ }^{2}$}

\author{
Laboratório de Estudos Urbanos - LABEURB \\ Núcleo de Desenvolvimento da Criatividade - NUDECRI \\ Universidade Estadual de Campinas \\ Rua Caio Graco Prado, 70 - 13083-970 - Campinas-SP - Brasil \\ mbarbai@terra.com.br ; m.fernandaaa@hotmail.com
}

\begin{abstract}
Resumo. Apresentamos neste trabalho uma análise da produção dos sentidos das palavras "privado" e "privacidade" e a série de verbetes autorais, polissêmicos e discursivos que construímos para compor a ENDICI. Para além dos sentidos já constituídos, buscamos trazer no confronto do simbólico com o político, outros sentidos, os do tempo em redes. Na pesquisa discursiva que deu origem aos verbetes quisemos compreender: 1. quais são os sentidos atuais dessas palavras quando neste espaço material que se sustenta na segregação e faz a manutenção do controle social; 2. como se formulam os discursos reguladores da mídia cada vez mais munida de tecnologias de vigilância, ou seja, qual a lógica que sustenta as atuais políticas de gestão do mundo íntimo dos indivíduos; e 3. como se exerce a (in)gerência dessa mediação pelo Estado, que se omite frente a tantos litígios?
\end{abstract}

Palavras-chave: enciclopédia; privado; privacidade; ciberespaço; controle social.

\begin{abstract}
This work presents our analysis of the process of production of meanings for the words "privacy" and "private", as well as the number of copyright entries that were built to compose ENDICI, all of which are polysemic and discursive. In addition to the directions already established, we sought to bring within the symbolic confrontation with the political other meanings regarding the time on networks. According to the discursive research that produced entries we wanted to understand: 1.the current meanings of these words when reported to this material space based on segregation and maintenance of social control; 2 . how to formulate regulatory speeches on media that os increasingly provided with surveillance technologies, i.e., the logic that supports the current management policies of the intimate world of individuals; and 3. how the mismanagement of this mediation by the state is carried out without considering so many disputes.
\end{abstract}

Keywords: encyclopedia; private; privacy; cyberspace; social control.

\footnotetext{
${ }^{1}$ Doutor em Linguística (Unicamp). Pesquisador do Laboratório de Estudos Urbanos do Núcleo de Desenvolvimento da Criatividade (Unicamp) e docente no Mestrado em Divulgação Científica e Cultural (MDCC/IEL/Labjor-Unicamp).

2 Pesquisadora de Iniciação Científica do Laboratório de Estudos Urbanos (Labeurb) do Núcleo de Desenvolvimento da Criatividade (NUDECRI), da Universidade Estadual de Campinas.
} 


\section{Introdução}

Neste artigo, buscamos, a partir do relato de nosso percurso de pesquisa, reunir e explicitar algumas reflexões que conduziram a escrita dos verbetes "privado" e "privacidade" para a ENDICI (Enciclopédia Discursiva da Cidade). Visamos com este trabalho compreender a produção de sentidos através de uma pesquisa situada no campo teórico e metodológico da Análise de Discurso com enfoque nas palavras "privado" e "privacidade" em tempos de rede. Pudemos, assim, observar a memória discursiva, os deslocamentos e atualizações de sentido e o funcionamento presente na discursividade dessas palavras. Em consonância com os objetivos da ENDICI, a partir desta pesquisa, construímos uma série de três verbetes autorais, polissêmicos e discursivos, sendo "privatização" o terceiro termo definido.

Autorais porque assumimos aqui a tarefa de produzir o efeito provisório de fechamento dos sentidos ao mesmo passo em que quisemos instalar nossa singularidade. Nós os estruturamos a partir, por um lado, dos sentidos já-lá (interdiscurso), e, por outro, pelos sentidos re-significados (deslocamentos). Dessa maneira, nos responsabilizaremos pelo que foi dito e pelo que foi silenciado (LAGAZZI-RODRIGUES, 2006 apud ORLANDI, 2006, p. 93).

Polissêmicos porque estruturados a partir do confronto de diferentes interpretações de um mesmo objeto simbólico, constituído a partir de um corpus heterogêneo, baseados nas múltiplas relações de sentido de um mesmo item lexical.

E discursivos porque, ao empreendermos uma pesquisa de base para a construção dos verbetes, confrontamos saberes especializados no urbano e saberes cotidianos com a perspectiva do saber resultante das análises. E pudemos, através da prática do definir, inscrever certa posição ideológica na memória discursiva e fazê-la circular. Conforme Orlandi (2003, p.26), fazemos isto "para interferir na relação do sujeito com o interdiscurso, para que tenha efeitos, no sujeito e na memória do dizer", para que nossos sentidos ressoem.

É sobre o processo de escrita desses verbetes que centralizamos neste artigo nossas reflexões a respeito dos sentidos possíveis para privado e privacidade.

\section{Apresentação}

O presente trabalho começou com o projeto "Os sentidos da palavra segurança nos dicionários brasileiros do século XIX e XXI", iniciado em abril de 2013 e finalizado em março de 2014. Este projeto foi vinculado ao Programa Bolsa Auxílio-Social (BAS) do Serviço de Apoio ao Estudante (SAE) da UNICAMP.

Este projeto, solicitado pelo Prof. Dr. Marcos Aurelio Barbai, inserido na área "Acervos, Arquivos e Biblioteca", teve por objetivo compreender as questões de segurança a partir de uma perspectiva que levasse em consideração a história da ideia de segurança. Além disso, funcionou como instrumento de auxilio ao trabalho de pesquisa a ser desenvolvido para a ENDICI: a escrita de um verbete para a palavra segurança e 
os termos que a ela se relacionavam.

Essa bolsa de trabalho, desenvolvida em 60 horas mensais, previa a participação de uma estudante para auxiliar o pesquisador no trabalho de acesso, seleção e consulta ao acervo de dicionários do CEDU (Centro de Documentação Urbana, do Laboratório de Estudos Urbanos).

Atendendo a estas tarefas, desenvolvemos o projeto em duas partes: leituras básicas, que apresentassem tanto os fundamentos da Análise de Discurso quanto seu funcionamento em análises já desenvolvidas. Em seguida, tivemos acesso às gravações que compõem o acervo do Labeurb das oficinas de redação anteriores, em que os participantes discutiam o processo de análise e redação dos verbetes para a Enciclopédia - visando preparar as condições de produção para o acesso e leitura de um arquivo. Por fim, detivemo-nos à consulta da palavra "segurança" nos dicionários selecionados. A isso se somou a participação em oficinas de redação de verbetes, parte em que tivemos maior contato com a proposta da ENDICI (projeto aprovado pela Fapesp, processo 2012/22917-0).

Também participamos de espaços como a oficina em que o professor Eduardo Guimarães, após expor sua pesquisa, discutiu seus verbetes cujos índices eram "cidade, cidadania, habitante". Houve também a I Jornada ENDICI, na qual foram apresentados os resultados parciais do projeto e alguns verbetes já redigidos.

Participar dessas atividades nos possibilitou uma grande aproximação entre nossos interesses e a proposta da ENDICI. Isto se deu porque consideramos de extrema relevância a exploração da polissemia, a busca de diferentes interpretações diante de um mesmo objeto simbólico, a criação de um espaço que possibilite que o sentido seja sempre outro, que os efeitos de evidências se desautomatizem. Que permita, dessa forma, retomadas e reformulações dentro de suas definições, uma vez que "nota-se também que os verbetes de certo modo constroem a sociedade, de maneira que o dicionário apresenta um horizonte de prospecção, o que caracteriza seu potencial transformador quando inserido em um espaço linguístico-histórico" (NUNES, 2006, p. 16).

Finalizado este projeto, submetemos a proposta da pesquisa aqui finalizada à FAPESP $^{3}$, a fim de desenvolver outra pesquisa que fundamentasse a construção do verbete privacidade na internet para a ENDICI, seguindo a proposta de leitura prismática que pressupõe o estudo das discursividades da cidade, fundamentado na Análise do Discurso, na construção da definição. Para tanto, detemo-nos aqui à investigação do processo de produção da monofonia dos sentidos de privacidade em rede, partindo do estudo da definição, com dicionários de língua portuguesa do século XVIII ao XXI, e da atualização do dizer, materializada pelos contratos que mediam a navegação de usuários em redes sociais, no caso, os Termos de Serviço e as Políticas de Privacidade de três empresas de comunicação: Google, Facebook e Microsoft. Neste processo, delimitamos a temática da pesquisa, construímos um arquivo próprio de análise e realizamos outras leituras fundamentais conceituais e analíticas dentro da Análise de Discurso.

Em seu desenvolvimento, notamos que os sentidos das palavras selecionadas se

\footnotetext{
${ }^{3}$ Aproveito o ensejo para agradecer a Fundação de Amparo à Pesquisa do Estado de São Paulo, que tornou possível este trabalho (Processo FAPESP nº. 2014/08824-5).
} 
dispõem em uma rede de significações na forma de uma teia discursiva. Nela, uma palavra determina e constitui sua significação na relação com outras. Por exemplo, meu percurso de análise permitiu observar que a palavra propriedade dá sentido à palavra privado. É possível notar esta relação a partir dos sentidos dos dicionários que retomam as noções de posse ("que pertence a um indivíduo particular" (HOUAISS, 2001, p. 1553)) ou de falta ("despido" (VIEIRA, 1873, p. 949), "falto, desprovido" (LIMA; BARROSO, 1946, p. 1006; FREIRE, 1939, p. 4134), "despojado" (MORAES, 1949, p. 246), "a que se tirou coisa de que gozava" (NASCENTES, 1952, p. 577), "desapossado" (HOUAISS, 2001, p. 1553)). É a partir desta relação que se faz possível os sentidos de privacidade, que retoma sentidos como "particular" (HOUAISS, 2001, p. 1553).

Além disso, mesmo que todas elas estejam ancoradas no ideal de segurança, trazem em sua espessura semântica os sentidos de violação de direitos, de exposição, de litígio. É o que se pode observar sobretudo nos exemplos nada casuais materializados no verbete "privacidade": "invadir a p. de alguém" (HOUAISS, 2001, p. 1553).

Observamos também, através da análise dos termos de serviço das empresas de tecnologia e informação, o papel central do contrato que cada indivíduo deve assinar (clicar) para adentrar e viver a sociabilidade gerada pela rede. Esses são os Termos de Serviço. Na leitura deste material nos deparamos com seu funcionamento assimétrico, ainda que em um contexto em que deveria pautar a igualdade das pessoas (físicas e jurídicas) perante a lei, termos de direitos e deveres. Esse contrato de termo de serviços é administrado e marcado por uma massiva aceitação independente de seu conteúdo (ao ponto de considerarmos a hipótese de que muitos usuários quando se registram em redes de tecnologia e comunicação não tomam ciência do contrato que estão assinando).

Consideramos que esse espaço segrega, dispõe os sujeitos dentro ou fora do campo de sociabilidade, produz desigualdades - uma vez que a não confirmação de identidade nas plataformas das grandes empresas de comunicação on-line (Google, Facebook e Microsoft) simplesmente impossibilita o acesso do sujeito a diversos produtos e dispositivos, como computadores, celulares e aplicativos. Ainda tivemos contato com uma parte fundamental dos Termos de Serviço, as Políticas de Privacidade, que, sem grandes explicações, explicitam muito sucintamente que nossos dados pessoais e práticas nas plataformas não são só apreendidos como interpretados e expostos a outros sujeitos e instituições, por conta de uma suposta melhoria dos serviços oferecidos. Esses documentos se sustentam na evidência do compartilhamento de dados e informações e são obrigatórios quando a apreensão de dados do usuário em massa é realizada pela empresa.

Como as palavras não possuem sentido em si mesmas, mas se os constituem em um processo simbólico, histórico e ideológico, elas sempre aparecem e significam na relação com as outras já ditas e que circulam no mundo. Isso fundamentou nossa escolha de prorrogar a finalização do projeto com a intenção de melhor explorar as redes de memória que circulam nos sentidos de privacidade, além dos sentidos de privado, verbete que passou a integrar nossas produções na ENDICI. Nesta primeira etapa, destacou-se a necessidade de um trabalho de análise mais detalhado em relação ao estudo da palavra privacidade. Além disso, foi necessário adequar a escrita dos verbetes ao funcionamento da ENDICI, considerando também o perfil de seus leitores: um público de especialistas em linguagem e o público em geral. 
Privado se mostrou uma palavra importante para as definições porque, para denominarmos privacidade, é preciso ainda trazer, para o dizer da palavra, os sentidos que circulam em relação à vida privada, à cena do cotidiano de cada um, da invenção em nosso cotidiano. Para isso, propusemo-nos, enquanto arquivo de pesquisa, trabalhar com os discursos que sustentam a obra História da vida privada no Brasil, particularmente o volume 3 .

Nessa etapa, reformulamos os dois verbetes apresentados, privado e privacidade; detalhamos o estudo realizado em relação aos sentidos da palavra privacidade, construímos um breve arquivo de análise para conhecer os sentidos de vida privada para melhor explorar as redes de memória que circulam nos sentidos de privado e de privacidade; e aprofundamos a pesquisa e a redação do verbete privacidade, que pode agora ir além das novidades do léxico.

Continuamos o trabalho situando-o nessa direção, a fim de não só conferir maior fluidez à leitura dos verbetes, como também redigir mais um verbete: privatização. Esta palavra tem em sua memória algo que transforma o público, pela noção de serviço e de política, em privado. Coletei material e realizei sua análise a fim de pensar o processo de constituição, formulação e circulação dos discursos acerca dela (envolvendo a mídia, os movimentos sociais, os partidos políticos e as empresas). Nesse processo, pudemos notar como ela é significada pelo privado e pela privacidade; como denota o processo de transformação do bem público em produto consumível ou prestação de serviço. Também observamos como regularidade os diversos escândalos pautando grandes irregularidades administrativas envolvidas nesse processo, que se dá entre governantes e empresários. Temos, como hipótese, que, em tempos de mercantilização dos direitos e bens comuns, as posições entre governantes e empresários foram (e são) muitas vezes coincidentes. Estaríamos sendo governados por administradores de empresas?

Como ruptura discursiva promovida em grande parte pelo acontecimento dos recentes crimes ambientais, houve alguns rearranjos em torno da palavra privatização, como, por exemplo, a desestabilização das ideia de mais verba disponível para ser aplicada com fins de manter os serviços e produtos, promover melhorias e garantir a eficiência dos serviços realizados pela empresa privada. Entraram em jogo sentidos de irresponsabilidade social e precarização, não só das condições trabalhistas como também dos serviços prestados e produtos produzidos.

Além disso, a partir desse processo, os direitos fundamentais são submetidos ao funcionamento da mercantilização, agindo sempre em função de maximizar ao extremo os lucros dos empresários e minimizar ao máximo os custos de produção (incluindo a busca pela isenção fiscal, a redução de salários, benefícios e direitos trabalhistas e a aquisição de matéria-prima de qualidade e barata).

Para a escrita dos verbetes, algumas questões foram levadas em consideração. A primeira diz respeito à prática de definir, que nos coloca em uma posição de autoridade frente ao sentido, nos permite inscrever nossa posição ideológica na memória discursiva, fazê-la circular.

A segunda diz respeito às tradições dessa prática, ou seja, de como, na história da lexicografia, as definições são realizadas. Isto exigiu, por exemplo, que fossem 
retomadas noções como hiperonímia e hiponímia, homonímia e sinonímia. Além disso, se colocou o confronto entre os sentidos que já figuraram para tais palavras e as novidades do léxico. Nesse sentido, iniciamos os verbetes a partir de seus sentidos mais gerais e então partimos para os mais específicos.

Também trouxemos, inicialmente, os sentidos mais recorrentes dessas palavras, em seguida as novidades e, por fim, alguns sentidos que não estão mais em voga. Fizemos isto por considerar o suporte material que abrigará as definições em sua escrita, ou seja, tendo em vista o fazer enciclopédico que busca, além de definir algo, trazer também uma visão a respeito de seu percurso histórico. Além disso, trabalhamos encadeando pesquisa com divulgação científica. Afinal, a definição discursiva surge a partir de análises e a escrita dos verbetes enfoca um público leitor diversificado, não apenas especializado.

\section{ENDICI}

A ENDICI é uma enciclopédia digital on-line, elaborada com base no dispositivo teórico da Análise de Discurso, sendo atualmente coordenada e organizada por Eni Orlandi (UNICAMP/UNIVÁS) e José Horta Nunes (LABEURB/NUDECRI/UNICAMP). Além de pesquisadores do LABEURBUNICAMP, integram o projeto participantes da Universidade Federal de Santa Maria (UFSM-RS), da Universidade do Vale do Sapucaí (UNIVÁS-MG) e da Universidade Católica de Brasília (UCB-DF). O que nos dá inclusive perspectivas para promover intercâmbio de atividades científicas.

Vale notarmos que o projeto já está em sua segunda fase. Na primeira, foram estabelecidas as diretrizes discursivas da ENDICI e também foram elaborados os primeiros verbetes resultantes de reflexões sobre um "glossário de base", em que os pesquisadores participantes definiram noções que os conduziram em suas reflexões e que produziram deslocamentos em relação ao já estabelecido nas disciplinas que falam da cidade. Além disso, recebeu também colaborações resultantes de um projeto denominado "Palavra, discurso e silêncio: no movimento dos sentidos urbanos", coordenado por José Horta Nunes (Processo FAPESP no 2009/15205). Os resultados desta primeira etapa de elaboração da enciclopédia estão apresentados no livro Por uma Enciclopédia da Cidade (ORLANDI, 2003).

Uma vez estabelecidas as bases da Enciclopédia e produzidos os primeiros glossários e verbetes, a atual fase do projeto objetiva dar continuidade às análises de textualidades urbanas e às produções de verbetes.

Os verbetes produzidos no projeto ENDICI, vale notarmos, é necessariamente constituído na relação com uma pesquisa discursiva em que cada pesquisador faz um recorte de análise, colocando questões e selecionando o material do corpus de acordo com os objetivos do projeto. Assim, cabe a cada participante, a partir de seu conhecimento da Análise de Discurso, montar o seu dispositivo de análise, atentar para as palavras da cidade e para os objetivos que direcionam o projeto. 
"Palavras da cidade" são os índices de discursividades urbanas selecionadas no início e/ou no decorrer da análise. Partindo já de algumas palavras ou de funcionamentos discursivos, elas funcionam como um horizonte de sentidos para o pesquisador. Assim, elas não são tomadas como itens lexicais fixados, mas como índices de processos discursivos que se explicitam durante a análise.

Isso faz com que a palavra selecionada funcione como ponto de um percurso que leva a outras palavras e discursos indefinidamente, até que se opere uma parada como final da análise, de acordo com o recorte efetuado e deixando-se aberta a possibilidade de outros sentidos. Aí reside a feição dinâmica e provisória dos verbetes, no sentido de que eles deixam espaço para retomadas e reformulações, o que tem consequências para o formato dos verbetes, a construção do banco de dados e o desenho do site que a hospeda.

No processo de análise privilegiamos a leitura prismática de arquivo, entendida como a leitura regida pela relação entre o discurso do senso comum, a dos especialistas e a nossa elaboração discursiva. E o faremos para interferir na relação do sujeito com o interdiscurso, ou seja, com os efeitos, no sujeito, do saber discursivo, da memória do dizer (ORLANDI, 2003, p. 26). Essa leitura colocará em relação os diferentes discursos da cidade, em confrontação com os materiais do corpus de cada pesquisador, e trará elementos para a formulação dos verbetes.

Uma vez efetuadas as análises, o passo seguinte foi a redação dos verbetes, considerados como textos de divulgação dos resultados de análise em direção a um público mais amplo. Visando a uma leitura não-linear, trabalha-se o hipertexto com diferentes formas de linguagem: enunciados, cores, sonorizações, volumes, espessuras, movimentos. Essas formas não são tomadas como exemplificação: "ligadas, linkadas, elas produzem sentidos, interferindo no modo de trabalhar as definições", possibilitando assim a desautomatização das evidências para o leitor. Trata-se de produzir e lidar com "texto-montagens móveis", ou seja, "espaços provisórios de ancoragem de sentidos, que arregimentam memória para os dizeres, ao mesmo tempo em que o retêm entre um quadro e outro, em uma outra montagem (possível) sempre latente".

Construída com base na perspectiva da Análise de Discurso, a ENDICI produz um conhecimento sobre a cidade enquanto objeto simbólico, passível de gestos de interpretação. Busca explicitar os processos de significação e as relações de sentido que se estabelecem na cidade e que envolvem espaços, tempos, sujeitos, instituições, materialidades diversas. Teoricamente, a Enciclopédia Discursiva da Cidade é uma tecnologia, um artefato, cuja especificidade está em "compreender o urbano através da linguagem" (ORLANDI, 2003, p. 7).

Especificamente no caso da pesquisadora que atuou enquanto colaboradora do pesquisador Marcos Barbai (LABEURB/NUDECRI/UNICAMP), um dos objetivos que guiaram o trabalho dela foi o de construir um verbete para os termos que se relacionam às palavras segurança, no caso, privado, privacidade e privatização. Visando observar como se dá a cena de enunciação definidora da palavra, trabalhamos com os dicionários dos séculos XIX ao XXI, querendo também pensar na administração realizada pelo Estado através de textos jurídicos, como Constituição Federal do Brasil de 1824 a 1988, além do Marco Civil da Internet. 


\section{Processo de análise}

\section{a. Dicionários}

A fim de pensar a atualidade e a memória discursiva no processo de definição e de constituição dos sentidos de privado e privacidade, consultamos os verbetes relativos a essas palavras em dez dicionários de língua portuguesa ${ }^{4}$. Os sentidos trazidos pelos dicionários em questão para privado demonstraram como a tensão entre o que é público e o que é privado é antiga; tanto quanto "o que é feyto em presença de pouca gente" (BLUTEAU, 1712, p. 750). Outros sentidos trazidos pelos dicionários não mais em voga hoje em dia dizem respeito a uma posição de conselheiro do príncipe, também denominado como "valido" ou "protegido".

A partir de Moraes (1813, p. 246), passou-se a definir privado pela falta. Então, privado passou a ser "quem se tirou coisa de que gozava", "o sujeito que de algo foi despojado, destituído ou desapossado". Só a partir de Aulete (1881, p. 793), no entanto, que privado passou a significar vida privada, particular, íntima. Essa ideia é fundamental para a noção de privacidade, que surge apenas no dicionário do último século, Houaiss (2001, p. 1553):

privacidade. s.f. (sXX) vida privada, particular, íntima <invadir a p. de alguém>. *GRAM trata-se de ang. de empréstimo recente na língua (talvez década de 1970), sugerindo-se em seu lugar o uso de intimidade, liberdade pessoal, vida íntima etc. *ETIM calcado no ing. Privacy'id.

A palavra está aqui como um sinônimo de vida privada: fica anunciada a abrangência que esse termo passa a ter, constituindo um campo próprio, uma esfera da vida, com suas próprias regras éticas e morais, seundo as quais novamente se demarca a propriedade individual, particular e pessoal. $\mathrm{O}$ exemplo trazido em seguida é bastante significativo também. Faz menção ao litígio ${ }^{5}$ concebido como tal desde 1946, com a Declaração de Direitos Humanos, que, em seu $12^{\circ}$ artigo, postula: "ninguém será sujeito a interferências em sua vida privada, em sua família, em seu lar ou em sua correspondência, nem a ataques à sua honra e reputação. Todo ser humano tem direito à proteção da lei contra tais interferências ou ataques". Ressoa, dessa forma, como a

\footnotetext{
${ }^{4}$ A saber, Vocabulário Portuguez e Latino (BLUTEAU, 1712); Dicionário de Língua Portuguesa (SILVA, 1813); Grande Dicionário Portuguez ou Thesouro da Língua Portugueza (VIEIRA, 1871-1874); Dicionário Contemporâneo da Língua Portuguesa (AULETE, 1881); Novo Dicionário da Língua Portuguesa (FIGUEIREDO, 1925); Grande e Novíssimo Dicionário da Língua Portuguesa (FREIRE, 1939-1944); Pequeno Dicionário Brasileiro da Língua Portuguesa (LIMA; BARROSO, 1946); Dicionário de Língua Portuguesa (NASCENTES, 1961); Novo Dicionário Brasileiro Melhoramentos Ilustrado (PRADO E SILVA, 1964); Novo Dicionário da Língua Portuguesa (FERREIRA, 1975) e Dicionário Houaiss da Língua Portuguesa (HOUAISS, 2001).

5 Pensamos litigio seguindo a indicação de Rancière para se pensar o dissenso: "os casos de desentendimento são aqueles em que a disputa sobre o que quer dizer falar constitui a própria racionalidade da situação de palavra. Os interlocutores então entendem e não entendem aí a mesma coisa nas mesmas palavras. Há todas as espécies de razão para que um X entenda e não entenda ao mesmo tempo um Y: porque, embora entenda claramente o que o outro diz, ele não vê o objeto do qual o outro lhe fala; ou então porque ele entende e deve entender, vê e quer fazer ver um objeto diferente sob a mesma palavra, uma razão diferente no mesmo argumento" (RANCIÈRE, 1995, p. 12). Dito de outro modo, além de ser a tirania do sentido, o consenso é uma ilusão.
} 
privacidade, em 2001, já era definida pelo inseguro. O mundo enn nossa volta parece suficientemente hostil e a invasão é eminente. Isto, vale notarmos, dá sentido e cria a necessidade de cuidados especiais, de ferramentas e serviços que assegurem as fronteiras com o público e garantam que essas informações ou não sejam descobertas ou não sejam divulgadas.

Isto nos mostra que o discurso das novas tecnologias da informação e da comunicação não só mercantiliza os direitos a privacidade como também aprisiona o sujeito, controla, vigia, oprime. (DIAS, 2011, p. 23).

\section{b. Contratos}

Nós nos reservamos todos os direitos não expressamente concedidos a você. (Declaração de Direitos e Responsabilidades, Facebook, 2014-2016, p. 3)

Os contratos que selecionamos para analisar consistem nos Termos de Serviço, contrato firmado para navegar em rede, e nas Políticas de Privacidade, parte específica do Termo que detalha como as empresas de tecnologia lidam com as informações pessoais apreendidas em massa. Sem aceitá-los, vale notarmos, não é possível ingressar na rede.

Gerenciar a privacidade dos usuários sob o funcionamento da prestação de um serviço firmado em contrato produz alguns efeitos. Um deles é encarar a privacidade como um serviço e, assim, submetê-la à lógica do mercado, orientada para a redução ao máximo dos custos de produção (garantia de insumos governamentais) e ampliação do preço cobrado por ele. Isto incorre na precarização do trabalho (condições, direitos, benefícios, salários) e na aliança entre Poder Público e empresários, que nos deixam a dúvida: quem são gestores públicos e quem são os empresários?

Notamos neste percurso a relação do usuário com empresas frente aos serviços prestados, marcada pela assimetria entre as partes. E, portanto, o compromisso firmado no início do uso não é o mesmo que vai estar em voga durante o uso dos serviços. De modo proporcionalmente inverso, há o aumento das responsabilidades do usuário e a isenção da empresa. Há uma inquietação em respeito aos direitos autorais dos desenvolvedores e sobretudo dos proprietários dos sistemas, em que fica bastante demarcada a preocupação especial em impedir a lucratividade de outrem a partir dessa prática.

À mercantilização dos direitos pelos sistemas de informações que os transformam em serviços ou produtos, ligam-se também a apreensão e o comércio de dados realizados com fins de depreender comportamentos, traçar perfis e prever possíveis ações dos sujeitos.

As finalidades declaradas pelas quais as empresas realizam tal captura de dados se dividem em três: confirmação da identidade do usuário; proteção contra usos malintencionados e promoção de melhorias nos serviços prestados. Partindo da ideia de que 
sejam as informações pessoais do sujeito que demandem proteção, nos perguntamos aqui: quais são os riscos? Quem os oferece? Nossa hipótese é a de que a figura que condensa em si a ameaça são os outros usuários do serviço em questão (individuais ou coletivos). A produção da evidência desta figura enquanto necessariamente ameaçadora mascara e disfarça a atuação da empresa quanto a seus serviços de comunicação, tal como a alteração, a exposição ou destruição das informações pessoais do usuário, que já é o que acontece.

Além disso, a Microsoft coloca que, se o usuário não concordar com os termos propostos pela empresa, não possui meios de interferir na dinâmica proposta, fica convidado a se retirar. Ou seja, se você não está de acordo, você "poderá" não usar tais serviços. Esse funcionamento responsabiliza o usuário inclusive pela sua disposição dentro ou fora do sistema e a trata como questão individual, escolha pessoal.

Dessa forma, funciona o processo de segregação deste espaço social de interação. Para além de conseguir acessar a internet e possuir uma conta na plataforma digital em que são oferecidos serviços on-line, é necessário submeter-se às regras de conduta que podem vir a impedir a participação permanentemente (conforme avaliado pela empresa). Assim, as empresas de comunicação legitimam e exercem seu poder de definir o que é permitido ou não, o que é seguro ou não, e solucionar os litígios neste espaço.

Na estratégia de individualização do sujeito para ser controlado, fica ressaltada a intenção de cruzar a maior quantidade de informações possíveis (considerando todos os serviços que hoje em dia dispõem dessas tecnologias) a respeito de determinado usuário. De saber exatamente quem ele é, o que ele faz e ainda pressupor muitas outras coisas a partir de sua atividade e de outros tantos milhões de informações.

Também é relevante marcar que, neste processo, não se dá apenas uma duplicação dos dados enviados pelo usuário, mas cria-se outro registro: acopla-se aos dados disponibilizados pelo usuário uma série de informações de monitoramento a respeito do uso por ele efetivado. Deixa de ser um backup ${ }^{6}$ e passa a ser um $\log$ de dados $^{7}$. Este arquivo deixa de ser apenas uma cópia do que é enviado e torna-se um registro de ocorrências, inscreve-se no campo da vigilância.

A apreensão dessas informações realça a concepção de controle e vigilância; afinal, realmente temos nossos passos e práticas seguidas, copiadas e armazenadas. Além de vinculados a nós enquanto pessoas.

O mecanismo de personalização e o sistema de bolha de filtros atualiza outro importante mecanismo de controle social de gestão da memória coletiva: deposita nas "mãos" dos meios de comunicação e influi diretamente no controle do fluxo de informações (baseados sobretudo na sua circulação). Assim, oculta-se determinadas notícias e espetaculariza-se outras. As relações políticas passam a funcionar pelo marketing, pela propaganda e pela manobra de massas.

Por fim, as empresas expressam com quem tais informações são divididas a partir

\footnotetext{
${ }^{6}$ Cópia de segurança realizada em sistemas informatizados para impedir a perda de dados.

${ }^{7}$ Expressão utilizada para descrever o processo de registros de eventos em um sistema computacional, a fim de que ele seja restaurado ou diagnosticado a partir das práticas dadas naquele espaço.
} 
de suas razões: 1. processamento externo (que já confronta com as leis do Brasil, por exemplo); 2. conforme requisitado pela lei; e 3. de "boa-fé", quando a empresa detentora dos dados acredita que está agindo para detectar, impedir ou abordar fraudes, proteger a segurança e a propriedade da empresa. Quanto à segunda, atesta-se a submissão ao poder do Estado, mas mediante regulamentação específica, quando existente. A terceira é a mais indeterminada: a empresa se reserva uma carta em branco para utilizar quando julgar necessário. Nela, reforçam-se os sentidos de "doação", ou seja, apaga-se a dimensão econômica da atividade através da indeterminação da proposição representada pela expressão "boa-fé". Na exposição de suas razões, no entanto, destaca-se proteger a segurança e a propriedade da empresa. Tal como em outros espaços relativos ao domínio comercial e mercantil, mais que os litígios que podem se dar neste espaço, mais do que os processos de segregação que a própria empresa pode inclusive promover, o desejo de ampliação da propriedade e o terror frente à sua subtração guiam as políticas de segurança e de (invasão à) privacidade das empresas.

Interessante, por fim, destacar a indeterminação dessa seção: a proposta do documento nesta parte é apresentar com quem essas informações são compartilhadas, mas, o que é realizado é discorrer sobre as razões que levam a este compartilhamento.

Assim se dão algumas faces do controle social realizado pelo Estado e também pelas empresas privadas de Comunicação, que definem o que é seguro e inseguro, o que é permitido e não permitido.

\section{Escrita dos verbetes}

Nossa proposta inicial de pesquisa era definir apenas a palavra privacidade. Isto se deu em grande parte porque concebemos as palavras selecionadas como um horizonte de sentidos para o pesquisador. Assim, elas não são tomadas como itens lexicais fixados, mas, como sequências semântico-lexicais, como índices de processos discursivos que se explicitam durante a análise. No entanto, no desenvolvimento da pesquisa, selecionamos outras palavras que se mostraram produtivas para se explicitar alguns funcionamentos discursivos, entendido como a lógica a partir da qual estrutura a produção de sentidos (privado e privatização).

Em nossa concepção, a produção de sentidos se dá a partir do contraditório jogo entre memória (constituição), atualização (formulação) e circulação (enquanto possibilidade de inscrição de sentidos na memória discursiva). Além disso, os sentidos das palavras se dispõem em uma teia discursiva: para falar de privacidade é necessário falar de privado. Quando se enfoca a privatização, o mesmo acontece, sendo necessário retomar sentidos de privado que imbricam em funcionamentos próprios de privacidade, como, por exemplo, a restrição de acesso e o enfraquecimento das fronteiras entre público e privado.

Um dos objetivos da elaboração dos verbetes é justamente trabalhar a diferença entre o sujeito da ciência e o sujeito da divulgação, sem apagar os processos de produção dos saberes e das ciências, sua historicidade, suas condições de produção, sua 
exterioridade.

Nesse processo de construção do verbete, buscamos confrontar os saberes especializados no urbano, os saberes cotidianos e o saber discursivo resultante das análises. Conforme Orlandi (2003, p. 26), o fizemos para interferir na relação do sujeito com o interdiscurso, ou seja, com os efeitos, no sujeito, do saber discursivo, da memória do dizer. Para tanto, construímos corpora de análise com os objetivos específicos de cada temática; analisamos discursivamente os corpora explicitando os sentidos que elas apresentam no discurso a partir dos conceitos e procedimentos analíticos (especificamente os de efeito metafórico enquanto substituições possíveis e de efeito de sustentação entendido como lógica que sustenta os enunciados).

Nesse processo de escrita, tomamos como princípio metodológico as noções de polissemia e de autoria. Polissemia é uma noção que traz condições para se compreender a multiplicidade de sentidos, explorando e confrontando diferentes interpretações de um mesmo objeto simbólico, redes de paráfrases, na tensão entre o mesmo e o diferente; sentidos específicos para diversas ocorrências de um item lexical. Na materialidade da Enciclopédia, isso também se faz presente através de dois ou mais verbetes com a palavras-entrada por diferentes autores, por exemplo.

A autoria, por sua vez, pode ser pensada a partir de C. Pfeiffer: ao pensar a relação cidade/escola, a autora propõe chamar de "sujeito urbano escolarizado" o sujeito que é autorizado a dizer pelo discurso da escola. Pfeiffer nota que, na escola, há um processo de simulação de posição de autoria, com a produção de uma posição discursiva já-dada de autoria, lugares "autorizados". E, fazendo um paralelo com o discurso do urbanismo, ela vê um funcionamento imaginário da mesma ordem, na medida em que há também a exigência do espaço de interpretação autorizado, com determinados ideais de construtores urbanos, de planejadores. Nessas circunstâncias, a autora propõe que:

[...] produz[amos] uma outra relação com a cidade, em que o político po[ssa] ocupar seu devido lugar enquanto possibilidade de, trabalhando na diferença, criar espaços públicos de conviviabilidade para que os sujeitos possam experimentar os sentidos da cidade material. (PFEIFFER, 2001, p. 33)

Por isso, na formulação dos verbetes, tivemos em vista, a partir do direcionamento proposto por Pfeiffer, a construção de posições de autoria para a cidade, que não estacionem em uma visão pré-definida pelo planejamento, mas que trabalhem, a partir da leitura prismática de arquivo, o confronto de diferenças, criando condições para o exercício da autoria na cidade e para a cidade, proporcionando o contato com as materialidades urbanas, tendo em vista os espaços públicos enquanto espaços de conviviabilidade e de circulação de sentidos.

Uma vez efetuadas as análises, o passo seguinte foi a redação dos verbetes, considerados como textos de divulgação dos resultados de análise, visando a um público diversificado, não especializado. Buscamos, dessa forma, interferir no modo de trabalhar as definições, possibilitando a desautomatização das evidências para o leitor. Trazendo para a materialidade de uma enciclopédia inclusive a heterogeneidade que tradicionalmente ela buscou tanto apagar. Ao mesmo tempo em que conferimos unidade ao discurso, pudemos inscrever nossa posição ideológica na memória discursiva, 
possibilitando sua circulação.

\section{Verbete}

\section{a. Privado}

Privado é um determinante, ou seja, é um adjetivo que diferencia, classifica e marca os limites entre o que é público e o que não é. Ele particulariza o substantivo de modo a denotar posse, indicar propriedade, sendo gerenciado a partir do funcionamento da privacidade, ou seja, a partir de restringir o acesso e permitir o usufruto apenas a alguns indivíduos, o que muitas vezes incorre na elaboração de mecanismos de confirmação de identidade (a exemplo de senhas e biometria). Isso faz com que algo se submeta à lógica do sigilo, da ocultação social e da proteção da divulgação pública. Um dos riscos que a publicização traz é a difamação e o ataque à imagem pessoal dos sujeitos.

Vale notarmos que os sentidos são imaginária e materialmente constituídos, ou seja, articulam as interpretações sobre os objetos (representações homogêneas, estereótipos) e o real dos objetos (heterogêneo, empírico) ( $c f$. ORLANDI, 2010, p.6). Isto, podemos dizer, delimita os sentidos de algo, articula em si forma e função, institui um corpo (que pode ser de um sujeito, de uma cidade ou de uma prática social).

Este corpo, independente de seu domínio, materializa e simboliza as relações de poder. No trabalho de Zoppi-Fontana e Cestari, "'Cara de empregada doméstica': discursos sobre os corpos de mulheres negras no Brasil", por exemplo, as autoras trazem a ideia de que os corpos dos sujeitos compreendem sua construção histórica. Isto quer dizer que o corpo surge e é significado na imbricação de traços que referem à ordem do racial (como a textura do cabelo, cor da pele, forma corporal), do cultural (como um tipo de penteado, de vestimentas, de calçados, de postura e forma de agir), do social (marcas de classe) e do gênero. Esse conjunto de fatores constitui o modo pelo qual eles produzem sentido sempre relacionados dentro da sociedade de forma desigual e hierárquica. Em geral, por fazer parte também da ordem da individualização dos sujeitos pelo Estado, toca sentidos como a relativa autonomia do sujeito em suas práticas. Essa dimensão política é muitas vezes apagada e, ilusoriamente, a individualidade se afirma como soberana em enunciados como "não tenho nada contra, é só questão de gosto".

As práticas sociais também são significadas pelas relações de poder. Neste domínio, segundo Fernando Novaes, em História da Vida Privada no Brasil ${ }^{9}$, elas se referem ao cotidiano e suas práticas culturais; tocam a transmissão de saberes (tradição oral, ensinamentos, técnicas), as manifestações artísticas (dança, música, novela), os hábitos cotidianos e sua relação com o corpo do sujeito (alimentação, vestuário, uso de substâncias psicoativas, saúde, higiene, relações sexuais), além da relação com o sagrado (religião, ritos, magia). Isso significa que ela tira seu sentido da valoração social que

\footnotetext{
${ }^{8}$ FONTANA-ZOPPI, M; CESTARI, M.J. "Cara de empregada doméstica": discursos sobre os corpos de mulheres negras no Brasil. RUA [online], Edição Especial, 2014. Consultada no Portal Labeurb, p. 172.

${ }^{9}$ NOVAIS, F.A. (Coord.). História da vida privada no Brasil. São Paulo: Companhia das Letras, 1997. p. 50 .
} 
prestigia uma e discrimina outras (chegando até mesmo a proibi-las para persegui-las).

O corpo da cidade também tem em si sua história. Nela a dicotomia casa $x$ rua se impõe. Acompanha os espaços privados e os públicos, os pessoais com os políticos, os gerenciados pelo sujeito e os gerenciados pelo Estado. No interior da habitação, por exemplo, funciona de diferentes maneiras, conforme sua espacialização: salas, quartos e cozinha dispostos em uma gradação mais ou menos gradativa entre privado e público, culminando no banheiro, instância máxima da privacidade.

\begin{abstract}
Ali prevalecem os metais brilhando com o design da moda, as louças e azulejos cujas superfícies lisas e polidas irradiam a sensação de limpeza, uma ênfase no utilitário, no funcional, no ágil e uma profusão de espelhos e reflexos que permitem a visão do ocupante por todos os ângulos. (NOVAIS, 1997, p. 50)
\end{abstract}

O movimento que associou higiene e saúde com o banheiro se valeu da lógica dessa incansável energia dispendida todo dia para produzir a exuberância física.

Mais recentemente, nos últimos quinze anos, com a massificação do acesso à internet e às redes sociais, privado é também as informações pessoais dos sujeitos que a utilizam e o registro de suas práticas (sites acessados, pesquisas realizadas - vinculadas com a data e hora em que o acesso ocorreu). Considerando que a internet chega apenas a 50\% das casas do Brasil (conforme dados do segundo semestre de $2015^{10}$ ), vale considerarmos que essa divisão também é constituída pelo político, ou seja, tem como efeito sua intensa valoração social que se sustenta na relação com a propriedade. Assim, funcionam os processos de segregação social.

Privado traz a ideia daquilo que não se tem acesso, daquilo que falta, daquilo de que se é desprovido, despojado ou destituído. Em um movimento inverso, também denota posse, propriedade, algo adquirido, próprio do sujeito. Ou seja, condensa-se assim, em um mesmo significante, antagônicas posições no seio das disputas sociais. Hoje, no dicionário de língua portuguesa Houaiss (2001), privado traz ainda a ideia de abundância, o que aponta o esvaziamento dos sentidos e dos espaços compartilhados: cada vez mais escassos, cada vez mais precários.

Em tempos de internet, do final do século XX ao XXI, abrange ainda as informações pessoais dos usuários da rede, o conteúdo referente a ele nas plataformas digitais e sua atividade virtual. Hoje, o ambiente privado se inscreve no registro da vigilância e é regido por códigos jurídicos que postulam a proteção de dados virtuais de seus usuários frente a alguém. Observamos essa constituição na forma pela qual se dá o acesso aos dados, ou seja, mediante autenticação, em que se dá a confirmação da identidade do usuário (através de usuário e senha ou, em casos mais recentes, da digital da pessoa ou do reconhecimento de sua aparência física).

Nos dicionários mais antigos, do século XVIII ao XX (BLUTEAU, 1712; SILVA, 1789; VIEIRA, 1871), a palavra privado assumia um sentido hoje já bastante distante e significava alguém: o conselheiro de um príncipe, o protegido de um soberano.

10 Conforme notícia do portal G1 <http://g1.globo.com/tecnologia/noticia/2015/09/pela-1-vez-acessointernet-chega-50-das-casas-no-brasil-diz-pesquisa.html $>$. 
Correspondia a um emprego e a uma posição social na sociedade monárquica. Também apareceu nos dicionários com o mesmo sentido pelas palavras áulico e válido.

\section{Referências}

FONTANA-ZOPPI, M; CESTARI, M.J. "Cara de empregada doméstica": discursos sobre os corpos de mulheres negras no Brasil. In: RUA [Revista do Laboratório de Estudos Urbanos do Núcleo de Desenvolvimento da Criatividade, on-line], Edição Especial, 2014. Consultada no Portal Labeurb.

NOVAIS, Fernando Antonio (Coord.). História da vida privada no Brasil. São Paulo, SP: Companhia das Letras, 1997.

ORLANDI, Eni. Discurso e políticas públicas urbanas: a fabricação do consenso. Campinas: Editora RG, 2010.

\section{Considerações finais}

Mostramos aqui o percurso que trilhamos em uma pesquisa que propiciou uma prática de iniciação científica inscrita em um projeto mais amplo apoiado pela FAPESP, expondo o processo de reflexão que fundamentou a construção dos verbetes privado e privacidade, para a ENDICI. A fim de fazer circular os resultados obtidos para além dos domínios acadêmicos, adotamos a proposta de leitura prismática a fim de interferir nos jogos de evidência do sentido, nas redes de filiação do dizer. Além disso, apostamos na Divulgação Científica enquanto instrumento de circulação do conhecimento produzido na academia materializados em verbetes que definem palavras da língua na relação com a cidade.

Desde então, detivemo-nos à investigação do processo de produção da monofonia dos sentidos de privacidade em rede, partindo do estudo da definição, com dicionários de língua portuguesa do século XVIII ao XXI, e da atualização do dizer, materializada pelos contratos que mediam o navegar em rede, no caso, os Termos de Serviço e as Políticas de Privacidade de três empresas de comunicação: Google, Facebook e Microsoft. Fizemos isso por considerarmos que o sentido se constitui a partir do confronto do que já foi dito (memória) com o que dele se desloca (atualização). Enfocando não só o ciberespaço como lugar de definição de palavras, temos então os dicionários de língua, por um lado, e os termos de prestação de serviço de outro.

Para além da palavra privacidade, em focada em razão de ter sido utilizada recorrentemente como argumento para litígios que se instalam atualmente no corpo da cidade, e de privado, porque traz em si sentidos que tornam possível a noção de privacidade, como, por exemplo, a noção de propriedade e a lógica da ocultação social, outros índices discursivos se fizeram produtivos para a elaboração dos verbetes (definições), uma vez que já enfocávamos os processos que tranaformam o público em privado. Foi assim que surgiu o verbete "privatização", palavra recente, das últimas três décadas, que põe em cena, não só os limites entre público e privado, como também o 
processo que transforma o primeiro no segundo.

Além do embate de sentidos, a partir dos processos de formação em linguística em questão, especificamente em análise do discurso, procuramos, no trabalho, sustentado em questões por nós estabelecidas, descrever e trabalhar o funcionamento dos discursos, o encadeamento de ideias, a lógica condensada que sustenta as formulações aqui analisadas/elaboradas. Compreendemos, assim, como se dão os processos de constituição da significação e, sobretudo, de que forma o modo pelos quais se apresenta uma ideia constitui os efeitos de sentido que são produzidos.

Pudemos também compreender como as relações de força se dão na linguagem, na definição de uma palavra através da tomada de posição do definidor, ou seja, de seus efeitos de identificação. Explicitamos ainda como o enunciado definidor representa um dizer de parte de uma sociedade e que se dá através do jogo, não só de constituição e de formulação, mas também da circulação do dizer.

Pudemos pensar nesse processo o acontecimento de linguagem, que é a palavra na medida em que, no ponto de encontro entre uma atualidade e uma memória, pode abrir espaço para a experimentação e para a descoberta. Além de que um enunciado definidor pode projetar um horizonte transformador quando situado em um espaço linguístico-histórico, ou seja, frente a formulações que não tentem apagar, pela homogeneização, suas condições de produção, sua exterioridade.

Interessante ainda notarmos a atualidade teórica e política da temática, uma vez que, pelo menos nos últimos três anos, assistimos a diversos acontecimentos no cenário nacional e internacional que colocaram em xeque a privacidade tal como era compreendida. Em junho de 2013, por exemplo, veio a público a prática ativa de espionagem pautada na interceptação da comunicação do governo dos Estados Unidos com o governo do Brasil. Em abril de 2014, o governo brasileiro reage à indeterminação jurídica, no que diz respeito às comunicações do ciberespaço, a partir do sancionamento do Marco Civil da Internet, em um evento internacional. Em março deste ano, face ao crescente de ataques públicos a personalidades governamentais, deu-se a publicização de uma escuta telefônica entre a presidente Dilma com o ex-presidente Lula, em rede nacional, possibilitada por diversas irregularidades jurídicas.

\section{Referências bibliográficas}

BluteAU, R. Vocabulário Portuguez e Latino. Lisboa: Colégio das Artes da Companhia de Jesus, 1712.

DIAS, C. e-Urbano: a forma material do eletrônico no urbano. Em: (Org.). Eurbano: sentidos do espaço urbano/digital [online], 2011. Consultada no Portal Labeurb, <http://www.labeurb.unicamp.br/livroEurbano/>, Laboratório de Estudos Urbanos, Núcleo de Desenvolvimento da Criatividade, Universidade Estadual de Campinas.

FONTANA-ZOPPI, M; CESTARI, M.J. "Cara de empregada doméstica”: discursos 
sobre os corpos de mulheres negras no Brasil. RUA [online], Edição Especial, 2014.

NOVAIS, F.A. (Coord.). História da vida privada no Brasil. São Paulo, SP: Companhia das Letras, 1997.

NUNES, J.H. Dicionários no Brasil: análise e história do século XVI ao XIX. São José do Rio Preto; Campinas; São Paulo: FAPERP; Pontes; FAPESP, 2006.

ORLANDI, E.P. (Org.). Discurso e políticas públicas urbanas: a fabricação do consenso. Campinas, SP: Editora RG, 2010.

Para uma enciclopedia da cidade. Campinas: Pontes; Unicamp/Labeurb, 2003.

ORLANDI, E.P. Discurso e texto: formulação e circulação dos sentidos. Campinas, SP: Pontes, 2001.

; LAGAZZI, S. Discurso e textualidade. Campinas, SP: Pontes, 2006.

PFEIFFER, C.R.C. Cidade e sujeito escolarizado. Em: ORLANDI, E.P. (Orga.). Cidade atravessada: os sentidos publicos no espaço urbano. Campinas, SP: Pontes, 2001.

SILVA, A. de M. Dicionário de Língua Portuguesa. $2^{a}$. ed. fotografada pela Revista de Língua Portuguesa, Rio de Janeiro, 1922.

Termos de Serviço [Facebook]. Disponível em <https://www.facebook.com/legal/terms $>$; acesso em jun. 2016.

VIEIRA, D.F. Grande Dicionário Portuguez ou Thesouro da Língua Portugueza. Porto: Casa dos Editores, 1871-1874.

VILLAR, M. de S.; FRANCO, F.M. de M.; HOUAISS, A. Dicionário Houaiss da língua portuguesa. Rio de Janeiro: Objetiva, 2001.

Artigo recebido em: junho de 2016.

Aprovado e revisado em: julho de 2016.

Publicado em: agosto de 2016

\section{Para citar este texto:}

BARBAI, Marcos Aurélio; MOREIRA, Maria Fernanda. A escrita de verbetes para a ENDICI: privado e privacidade. Entremeios [Revista de Estudos do Discurso], Seção Temática [Os discursos sobre segurança em meio a políticas e processos de significação], Programa de Pós-graduação em Ciências da Linguagem (PPGCL), Universidade do Vale do Sapucaí, Pouso Alegre (MG), vol. 13, p. 283-299, jul. - dez. 2016.

DOI: http://dx.doi.org/10.20337/ISSN2179-3514revistaENTREMEIOSvol13pagina283a299 